\title{
TEACHING OF CHEMISTRY AT SCHOOLS
}

T 'HE third Salters' conference of schoolmasters was organized and held during April 1-5, at the University of Bristol, with the help of Prof. D. H. Everett, Dr. F. H. Pollard and Dr. P. Woodward of the Department of Chemistry, and Dr. H. Knowles and Mr. W. S. James of the Department of Education. The aim of these conferences is to use the surroundings and facilities of university residence, to bring together a number of schoolmasters and schoolmistresses and to promote public and informal discussions about the great variety of present-day problems in the teaching of chemistry in schools. Forty-three members attended from public and grammar schools throughout the British Isles, and met members of the University of Bristol also concerned with these problems. Specialist lectures were given by Dr. F. H. Pollard on the "Chromatography of Inorganic Compounds", by Mr. G. R. Hall (Imperial College of Science and Technology) on "Radio-Chemistry for Schools", by Dr. J. T. Martin (University of Bristol) on "Insecticides", by Prof. A. R. Battersby (University of Liverpool) on "The Winds of Change", and by Prof. D. H. Everett on "The Use of Models in the Teaching of Chemistry".

Lectures which were intended to provide a basis for more general discussion were also given by Sir Willis Jackson (Imperial College of Science and Technology) on "The Importance of Chemistry to the Progress of Electrical Engineering", Prof. Ben Morris (University of Bristol) on "Science in Education", Mr. H. F. Halliwell (Nuffield
Research Fellow for chemical education) on "Some Problems of Chemistry Teaching in Schools", Dr. van Praagh (Christ's Hospital) on "Research Projects in School Chemistry", Mr. E. R. Coulson (chairman of the Association for Scientific Education's Chemistry Panel) on "The Aims and Objects of the New 'A' Level Chemistry Syllabuses"; and Mr. M. G. Brown (University of Nottingham) on "Examinations". In discussion, the subjects of "Examination Syllabuses" and "The Modern Approach to Chemistry Teaching" were debated at length and illustrated by members of the conference from personal experience.

To help them maintain a progressive outlook, many of the teachers of chemistry in schools, stimulated by discus. sions at this conference, voiced two general needs, both associated with the work of universities. One need is for the enlargement of provisions for sabbatical leave schemes, to enable a schoolteacher to return to the university, for a period of fresh stimulation and fresh grasp of his subjects. A second need is for more sustained contact with teachers in the universities in related subjects, in order to keep abreast of those modern developments in chemistry that are suitable for inclusion in school syllabuses, and in order to promote discussions of problems that arise in the teaching of chemistry. The view was expressed that the teacher of chemistry in a school is a person often isolated from the mainstream of scientific contact with university, industrial and Government establishments.

\section{ROLE OF BENTONITE IN CONCRETE RETAINING WALL CONSTRUCTION}

\begin{abstract}
THE 1,000-ft. long twin-tunnel underpass at $\mathbf{H y d e}$ Park Corner, London, is the major feature of the Hyde Park Corner-Marble Arch traffic improvement scheme carried out under the auspices of the London County Council and formally opened in October 1962. The construction of this tunnel presented some formidable problems, not the least of which were those due to proxim. ity of the escalator shaft of Hyde Park Corner underground station and of St. George's Hospital to the line of the underpass, and the paramount importance of noise. control so far as practicable for the sake of patients in the Hospital. To this end, the plan adopted was to construct the Piccadilly and Knightsbridge 'extremes' first; secondly, the tunnel sections in front of Apsley House and St. George's Hospital; finally, the 'linking' stations. The noisy method of pile-driving normal to a road-engineering project of this magnitude in the type of sub-soil characteristic of this part of London had, in these special circumstances, to be drastically restrained. The method actually adopted, with considerable success, in building the concrete retaining walls for subsequent open-cut tunnel excavation was what is known as the ICOS process, developed by the Impressa Costruzione Opere Spezializzate of Milan. This, in many respects novel, procedure is based on the use of bentonite, an internationally well known but commercially rather loosely described 'plastic clay'.

Bentonite is the name originally given to a specific type of clay occurring in the Cretaceous Fort Benton shale at Rock Creek, Wyoming, by W. C. Knight in 1898. Since that time it has been established that it was formed by devitrification and accompanying chemical alteration of a glassy volcanic ash, at least in its original native environment. Further, that the operative clay-mineral
\end{abstract}

in this material is montmorillonite, as is the case in Fuller's Earth, but in the constitution of bentonite, possessing strong moisture-absorption properties, making for plasticity and, with excess of water, bulk swelling and slime formation. It is in this last connexion that its value is exploited in the ICOS process which proved so beneficial in constructing the Hyde Park Corner underpass.

Briefly, the technique involved is to construct a concrete-lined guide trench, in this case $3 \mathrm{ft} .6$ in. $-4 \mathrm{ft}$. deep, laid out on the line of work. This acts as a guide for the grabs and also as a reservoir for bentonite mud emplaced therein. In the present instance, according to Concrete Quarterly (No. 56, p. 6; 1963), "A trench excavation, 20 in. wide and as much as $70 \mathrm{ft}$. deep in certain places, was then dug by special grabs, while the trench was kept filled with bentonite mud. This had the effect of stabilising the sides throughout the operation. Next, steel reinforcing cages were lowered into the bentonite-filled trench, and concreted by means of a tremic pipe displacing the bentonite suspension. Concreting was done in 16 - $\mathrm{ft}$. bays, a special pipe being used as a stop end for each bay". Once the retaining walls are thus concreted, the tunnel excavations can proceed, a specially dense concrete being used to ensure absolute water-tightness.

It is worthy of note that the southern leg of the underpass involved excavation within $2 \mathrm{ft}$. of the escalator shaft of Hyde Park Corner underground station and of the foundations of St. George's Hospital, which are only $12 \mathrm{ft}$. deep. The delicacy with which the excavations were accomplished resulted in only $\frac{1}{8}$-in. settlement of the hospital building and the maximum movement in the escala.tor shaft was never at any time greater than $\frac{1}{4}$ in., truly a remarkable achievement in the circumstances. 